\title{
Modeling of Arduino-based Prepaid Energy Meter using GSM Technology
}

\author{
Uzair Ahmed Rajput ${ }^{1}$ \\ Department of Electrical Engineering \\ QUEST Nawabshah Sindh Pakistan
}

\author{
Khalid Rafique ${ }^{2}$ \\ Director General Information Technology Board \\ Azad Jammu \& Kashmir
}

\author{
Abdul Sattar Saand ${ }^{3}$, Mujtaba Shaikh ${ }^{4}$, Muhammad Tarique ${ }^{5}$ \\ Department of Electrical Engineering \\ QUEST Nawabshah, Sindh, Pakistan
}

\begin{abstract}
It is realized that one of the defective subsystems adding to the tremendous budgetary loss in Power Supply Company is the conventional metering and charging framework. Mistakes get presented at each phase of charging the energy rates, similar to blunders with conventional meters, reading errors by human while noticing the consumed energy; and blunder during the preparation of paid and the due bills. The solution for this downside is a prepaid charging or billing framework of consumed energy. Most of the developing countries are shifting their conventional energy management practices to the modern one by replacing the old and conventional energy meters with the smart meters outfitted with the prepaid facility to quantify the power consumption so as to decrease the income deficits looked by utilities because of customer unwillingness to make consumed energy payments on time. Our proposed design embedded with Arduino and GSM technology is advancement over conventional energy meter, which enables consumer to effectively manage their electricity usage. The system performance is good with the acquired results. An earlier charging will undoubtedly get rid of the issues of unpaid bills and human mistakes in meter readings, along these lines guaranteeing justified income for the utility.
\end{abstract}

Keywords-Arduino; energy meter; smart meters; RFID; GSM

\section{INTRODUCTION}

Electric energy consumed by the power devices is measured by a gadget known as an energy meter. Since 1980s, the energy meter's journey started. When there were large energy meters which have been made with lots of innovations in energy meters to reduce its size and also the weight. Particularly, enhancement in accuracy, specifications and features of energy meters has been a topic of discussion.

In Pakistan, electromechanical energy meters were used for a long time. These meters work by checking and figuring the quantity of turns of an electrically directing metal plate which is made to rotate at a speed in respect to the power experiencing the meter. Those electromechanical energy meters are being supplanted by the newly digitized meters due to different problems like there is no way to upgrade those energy meters, its accuracy was limited and those meters were easy to manipulate because direction of revolving disc can be easily reversed. Nowadays, digital energy meters can measure voltage, current and power also but electromechanical energy meters can only measure active power. Digital meters measure energy usage by highly integrated circuits, by capitalizing the voltage and current that gives the instantaneous power in watts. Digital meters show usage of electricity in digits on a liquid crystal display and those meters are highly accurate, inexpensive, theft reluctant, etc.

This work is intended to gather the information about the data which is consumed energy of a specific user or consumer through a wireless communication system (not required to visit consumer premises), and the system is called as AMR (Automatic Meter Reading). The AMR system is proposed to remotely accumulate the meter readings of a locale using a relating remote wireless system without individuals physically going to and taking note of the readings of the meters [1].

\section{PROBLEM STATEMENT}

As we mentioned above several advantages of digital energy meters, but always there are chances of innovation or modification in different instruments for ease of consumer and supplier. Following are some problems observed in those energy meters which should be rectified:

- Meter reading and other related tasks like bill payment are performed by a large number of staff i.e., large number of employees are required.

- An expansive number of staff is utilized for meter reading and other related assignments like bill payment.

- Billing errors due to carelessness of meter readers during meter reading and sometime billing estimation.

- Consumer has to stand in queue for hours for bill payment.

- Careless usage of electricity by consumer who is unaware of its cost.

- Consumers are not bound to pay bill on time.

\section{HYPOTHESIS}

As a solution of above mentioned problems, "prepaid energy meters" are being introduced. As per a current report 
from Navigant Research, the overall introduced base of prepaid meters is required to add up to more than 85 million from 2014 to 2024 [2].

\section{EXISTING PREPAID SYSTEM}

\section{- Smart Card Based Prepaid Energy Meters}

In this type of prepaid energy meter, there are two main components; one is smart card and another one is smart card reader. Smart card is like credit cards made of plastic and it consists of different components like CPU, ROM, EEPROM, etc. so basically integrated circuit is embedded on a smart card [3]. There is a whole smart card operating system through which data is controlled of a smart card. In this kind of scheme, the consumer must recharge his card as much number of units he wants. Later, that card is inserted into card reader which is embedded with energy meter like a whole package. Afterwards, card reader does its work and stores the units which are available in smart card, energy meter reduces the units as much electricity is being consumed. When unit reaches to zero, it disconnects the electricity until recharge.

- Smart meters (prepaid meters) with GSM technology.

- In this sort of scheme, a message is sent to smart meters via GSM network by the consumers after recharging their cell phone account. As much amount (rupees) is sent to energy meter, it purchases number of units and those units are stored in energy meter. As consumer use electricity units are reduced by energy meter and when the purchased units are exhausted electricity is cut-off. When next recharge is sent over to energy meter, it recognizes the mobile number and decodes message, add number of units in its storage so as electricity is restored [4].

\section{RFID BASED SMART METER}

Radio-frequency identification (RFID) is a programmed recognizable proof strategy, depending on putting away and remotely recovering information utilizing gadgets called RFID tags or also known as transponders. The development requires some level of the coordinated effort of a RFID reader and the tag. A RFID tag is associated with or melded into a thing, animal, or a person with the true objective of recognizable proof and following using radio waves. A few tags can be read from a few meters away and past the line of sight (LOS) of the reader [5].

Following this strategy, the individuals utilize the RFID cards issued by the power providers. The energy could be purchased by recharging the novel RFID cards while utilizing the code in the card. At the point, when the buyer needs to utilize the electricity, he needs to demonstrate the card to the reader, at that point the one of a kind code inside the card is perceived by the reader, and begins deducting the RFID card amount according to the quantized unit charge. After utilization of whole amount, the consumer needs to recharge the RFID card again [5].

\section{PROPOSED SYSTEM}

\section{A. Benefits of the Proposed System}

There are many benefits for customer as well as for supplier of this project:

- Pay according to your current income situation.

- Reduce electricity consuming when income is tight.

- No billing errors.

- No debt money.

- No need of extra staff for meter reading.

- Customer will be responsible for disconnections.

\section{B. System architecture (B.D \& B.D Description)}

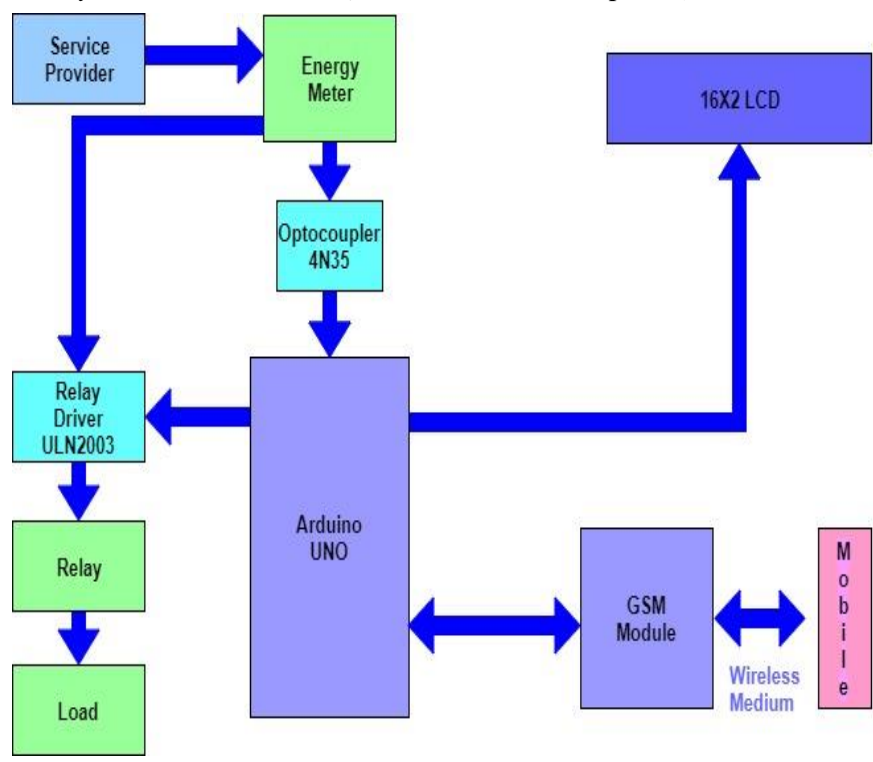

Fig. 1. Layout of prepaid energy meter.

This layout of Fig. 1 yields the idea behind prepaid energy meter scheme. It shows different hardware components incorporated, their connections and the data flowing in this scheme. In this layout, the energy meter is supplied by the service provider (WAPDA) and supplying the energy to the load through an electromechanical relay, which operates under certain conditions. Energy meter is also connected to the Arduino UNO in order to obtain the objective of automatic measuring the consumed energy and to perform the suitable action depends upon the current units available. Arduino UNO is additionally associated with the GSM Module for sending or receiving the SMS to the client for the status of their connection and to recharge the energy meter if it is required to do so. LCD is connected to the Arduino UNO board to display the current status of the connection so the costumer remains in touch with the information about the load and their purchased units [6]. 


\section{Methodology}

The entire Circuit diagram has been shown below in Fig. 2. The power is measured by the energy meter with respect to time and is calculated by multiplication of voltage and current signals. The IC of energy meter generates pulses according to real power utilization. This energy meter calculates $1 \mathrm{KWh}$ for $3200 \mathrm{impulses,}$ so rated as $3200 \mathrm{imp} / \mathrm{KWh}$, and there will be blinking of an LED for its every pulse. An Optocoupler has been connected to this LED so Optocoupler will be switched whenever LED blinks. We cannot directly connect energy meter's LED with Arduino because LED possesses analogue signals while we are feeding Arduino on the digital side. The pin number(D8) of Arduino is attached to the switching side of an Optocoupler for detecting pulses coming from energy meter. When a pulse occurs from energy meter, optocoupler is switched, pin D8 of Arduino detects a digital 0, otherwise it is not active and is in undefined state. There will be a count 1 to a data when there will be change on the state of the pin from digital 1 to 0 . We have interfaced GSM module with Arduino UNO. The data communication pins are RX and TX, Arduino's RX pin is connected with GSM module's TX pin and vice-versa. Before connecting GSM module with Arduino, a valid SIM card must be installed in SIM card port of GSM module. All ground pins GND are connected together. For switching purpose (ON/OFF) to supply a relay is being used. We cannot connect Arduino directly with relay because as Arduino has ATMEGA328P processor and its pins can supply roughly $25 \mathrm{~mA}$, Processor pins have large effective resistance and a high voltage will "drop" as increasing current is drawn and a low voltage will rise as load increases. Pins may be specific with a maximum short circuit current but at that point a high pin will be pulled low and a low pin will be pulled high so short circuit current has limited applicability. So, relay is connected with Arduino through ULN2003 IC or relay driver, ON/OFF instructions are sent over to relay driver by Arduino and it can turn ON/OFF relay. LCD is also interfaced with Arduino digital pins $(7,6,5,4,3,2)$ on which we can see how much units are purchased, remaining units and balance, etc. [7]. Fig. 3 shows the flow diagram of processes involved in prepaid energy meter scheme.

\section{E. Circuit Diagram}

See Fig. 2 below.

\section{F. Work flow}

See Fig. 3 below.

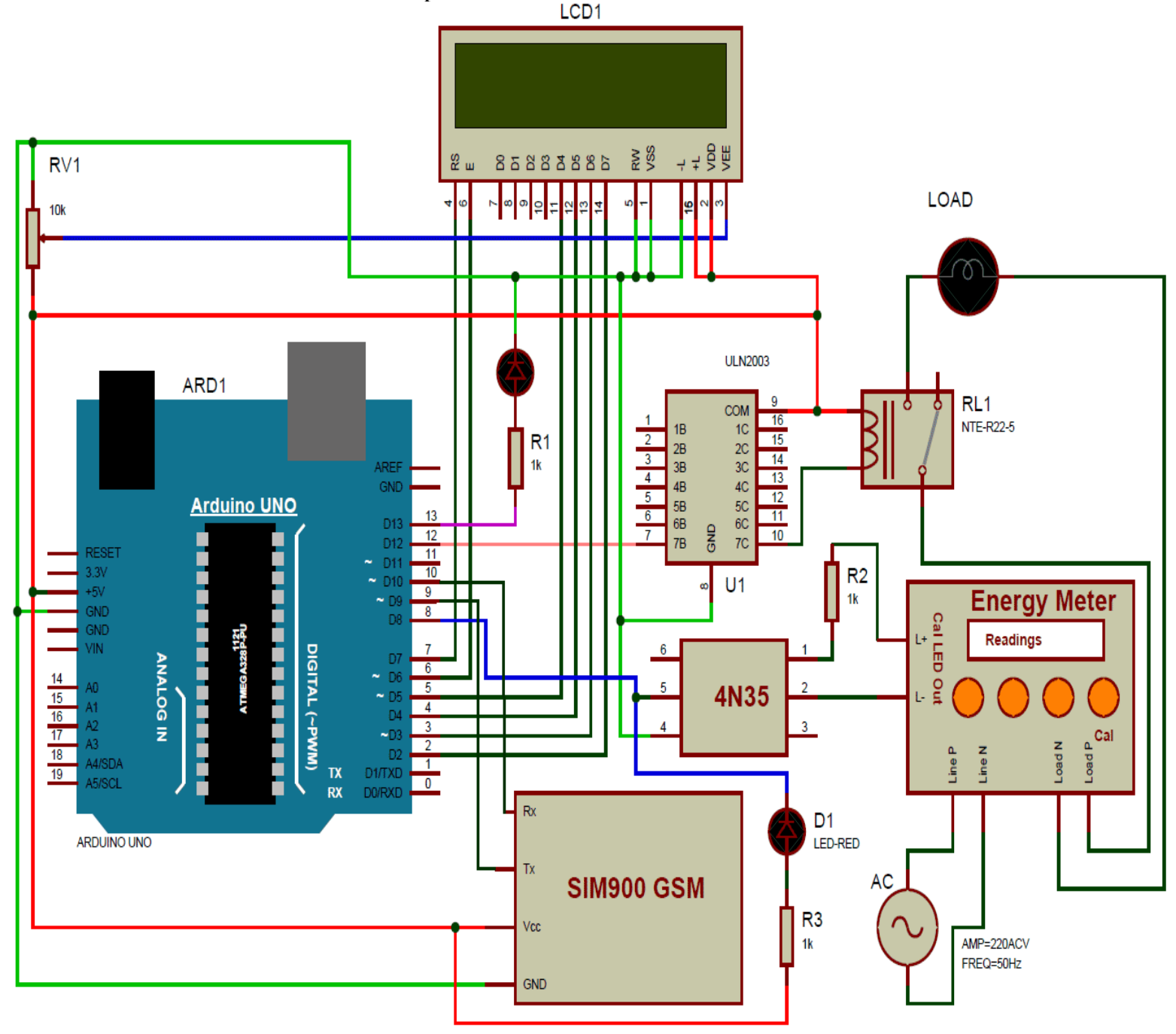

Fig. 2. Circuit diagram of prepaid energy meter. 


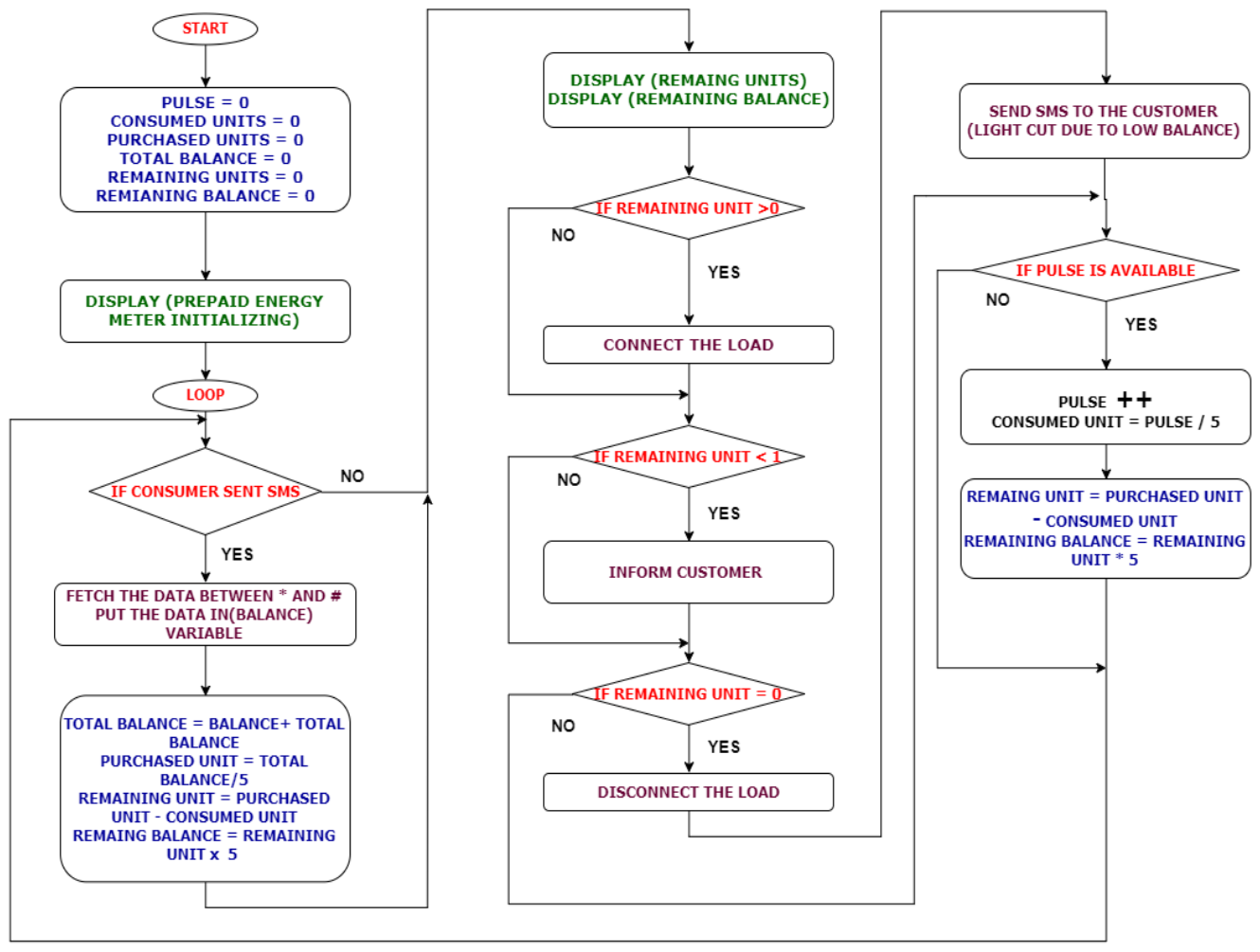

Fig. 3. Flow diagram of processes involved in prepaid energy meter scheme

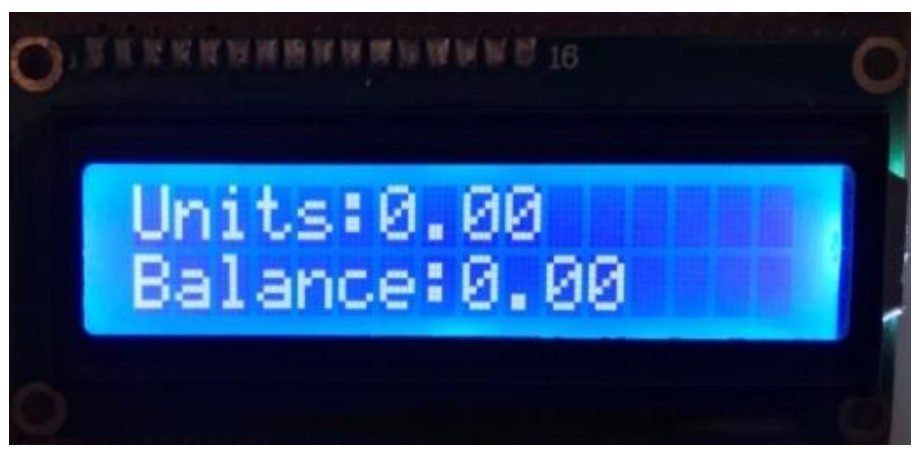

Fig. 4. Display zero units and zero balance.

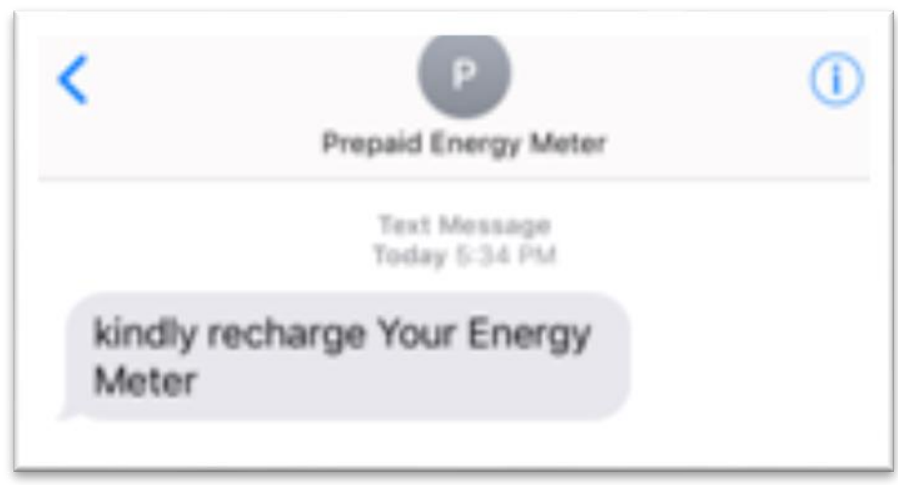

Fig. 5. No balance by sending an SMS through GSM module.
When there is no balance in energy meter as it would be at initial state or it can be when all the purchased units are consumed, the microcontroller will display zero units and zero balance as shown in Fig. 4. At the same time, it will inform the customer regarding no balance by sending an SMS through GSM module as shown in Fig. 5.

- When customer recharge some amount to the energy meter (Fig. 6)

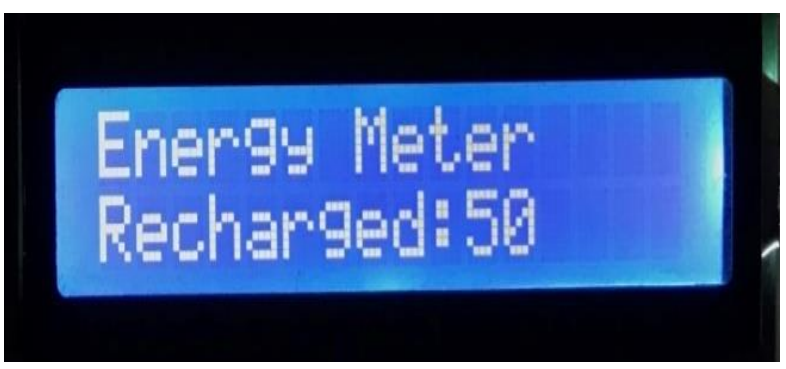

Fig. 6. When customer recharge some amount to the Energy Meter.

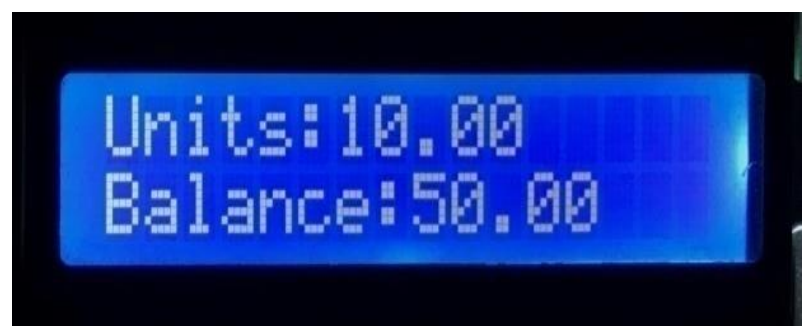

Fig. 7. Show credit. 


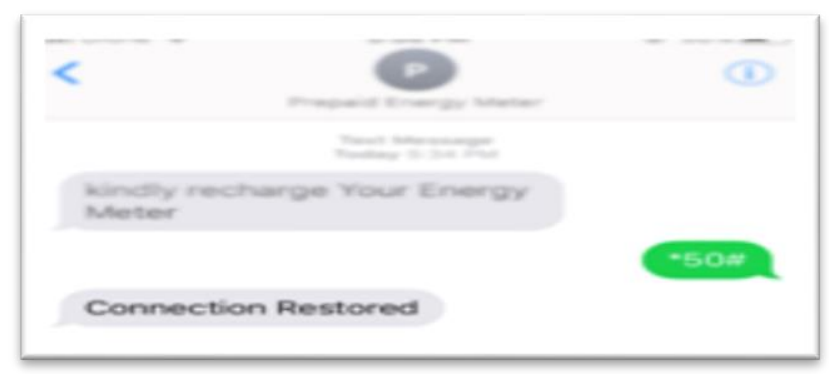

Fig. 8. An SMS is sent back to the customer.

When the customer recharges a certain amount by sending a message to the GSM module, it delivers that specific data to the microcontroller (i.e. Arduino UNO) so it can decode it and fetch the amount that customer wants to recharge his account. The recharged amount is displayed on LCD which is shown in Fig. 7.

After a certain process the microcontroller commands to connect the load to the supply as the balance in customer's account is sufficient to get the connection back, for this regard an SMS is sent back to the customer to inform him that their connection is restored as shown in Fig. 8.

- When energy meter cut off the load due to insufficient balance (Fig. 9)

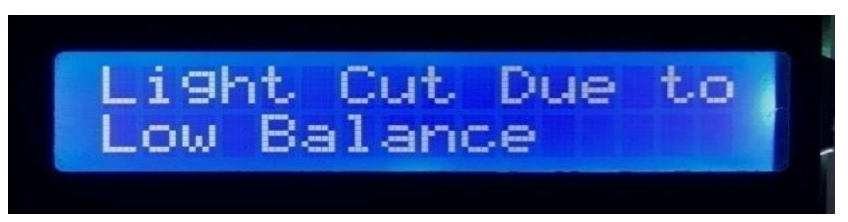

Fig. 9. When energy meter cut off the load due to insufficient balance.

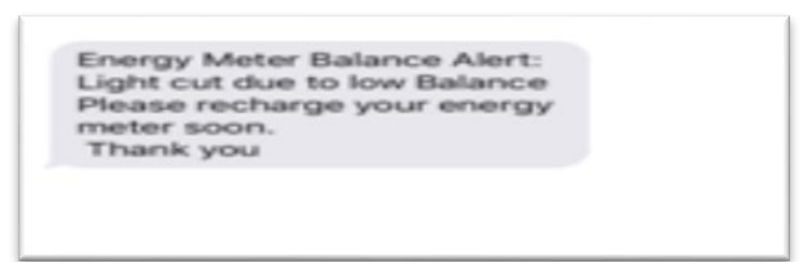

Fig. 10. SMS to inform the customer regarding the status of their connection.

The customer is bound to use as much amount of electrical energy as the balance he has in his account. As the balance in his account reaches zero value then it becomes insufficient to continue the electric supply to the load; that is why the microcontroller commands to disconnect the load from supply. A message about this disconnection of load is displayed on LCD and also sent by SMS to inform the customer regarding the status of their connection as shown in Fig. 9 and 10, respectively.

\section{CONCLUSION}

The advancement in power distribution system is non-stop process and new technology is always in progress. In this paper, an Arduino and a GSM based smart prepaid energy meter has been proposed. Units are purchased by using GSM technology and those units are deduced according to electricity usage. This project presents a single-phase energy meter for domestic consumers with prepayment billing method. The significant preferred standpoint is the capacity of this system to update the current conventional meters into smart prepaid meters with a connection of Arduino and GSM (Prepaid Module). This kills the need of totally supplant the energy meters. Cost is the main important factor of this work which is quite high but will reduce from 3 to 4 times after implementation of this project. Nowadays as power supply companies need labour for meter reading after implementing this, there will be no need of so many meter readers and lots of money will be saved.

The idea of prepayment electricity bill prior its usage is being gradually accepted around the world, and that's why the market for prepaid energy metering is growing. After having many advantages, this project still needs more safety check and modification especially the GSM module for the network coverage of SIM which is being used, should be strong so that the GSM can work properly.

\section{REFERENCES}

[1] Dike, Damian O., et al. "Minimizing household electricity theft in Nigeria using GSM based prepaid meter." American Journal of Engineering Research (AJER) 1 (2015): 2320-0936.

[2] https://www.navigantresearch.com/newsroom/prepaid-electric-metersareexpected-to-have-an-installed-base-of-more-than-85-million-from2014-to-2024

[3] M. W. Raad, T. Sheltami2 and M. Sallout, "A SMART CARD BASED PREPAID ELECTRICITY SYSTEM," in Pervasive Computing and Applications, 2007. ICPCA 2007. 2nd International Conference, Birmingham, 2007

[4] Omijeh, B. O., and G. I. Ighalo. "Modeling of gsm-based energy recharge scheme for prepaid meter." IOSR Journal of Electrical and Electronics Engineering 4.1 (2013): 46-53.

[5] R. Teymourzadeh, M. I. S and A. J. A. Abueida, "RFID-BASED Prepaid Power Meter," in 2013 IEEE Student Conference on Research and Development (SCOReD, Putrajaya, 2013.

[6] Sheelasobanarani, Dr K., et al. "A Prepaid Energy Meter for Efficient Power Management." International Journal of Emerging Technology and Advanced Engineering 4.3 (2014): 593-595.

[7] Rodrigo, W. D. A. S., et al. "A prepaid energy meter using GPRS/GSM Technology for improved metering and billing." International Journal of Computer Science and Electronics Engineering (IJCSEE) Volume 4 (2016) 